\title{
Impaired expression of Toll-like receptor 2 in nontuberculous mycobacterial lung disease
}

\author{
Y.J. Ryu**,, E.J. Kim*,ף, S-H. Lee*, S.Y. Kim*, G.Y. Suh*, M.P. Chung*, H. Kim*, \\ O.J. Kwon* and W-J. Koh*
}

ABSTRACT: The aims of the present study were to investigate the expression of Toll-like receptor (TLR)2 on the peripheral blood monocytes of patients with nontuberculous mycobacterial (NTM) lung disease and healthy controls, and to assess the responses of these monocytes to TLR2 agonists such as Mycobacterium avium and lipoteichoic acid (LTA).

Reverse transcriptase-PCR was used to analyse TLR2 mRNA expression in peripheral blood monocytes from 17 NTM patients and 10 healthy controls. mRNA and protein secretion levels were also determined for the cytokines interleukin (IL)-12 p40 and tumour necrosis factor (TNF)- $\alpha$.

Expression of TLR2 mRNA by peripheral blood monocytes after stimulation with $M$. avium or LTA was lower in NTM patients than in healthy controls. IL-12 p40 and TNF- $\alpha$ mRNA and cytokine secretion levels were also lower in patients than in healthy controls. Treatment with anti-TLR antibody decreased $M$. avium- and LTA-induced IL-12 p40 and TNF- $\alpha$ production in healthy controls, but not in NTM patients.

The present results suggest that the downregulation of Toll-like receptor 2 and the resulting decreased production of interleukin-12 p40 and tumour necrosis factor- $\alpha$ following Mycobacterium avium or lipoteichoic acid stimulation may contribute to host susceptibility to nontuberculous mycobacterial lung disease.

\section{KEYWORDS: Atypical mycobacteria, disease susceptibility, lung diseases, Toll-like receptor 2}

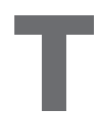
he incidence of lung disease caused by nontuberculous mycobacteria (NTM) appears to be rising worldwide, but it is unclear whether this is due to enhanced detection or to actual increases in the burden of infection [1-4]. Lung disease due to NTM commonly occurs in structural lung disease, such as chronic obstructive pulmonary disease, tuberculosis and pneumoconiosis. NTM lung disease also occurs in females without clearly recognised predisposing factors $[5,6]$. Although bronchiectasis and NTM infection often coexist in these patients (nodular bronchiectasis), it remains controversial whether bronchiectasis is truly caused by NTM infection or is a predisposing condition favouring NTM infection [1, 2].

NTM are ubiquitous environmental organisms. Since exposure to these organisms is universal and the occurrence of disease is uncommon, normal host defense mechanisms must be effective enough to prevent the infection [5]. Therefore, otherwise healthy individuals who develop NTM lung disease are likely to have specific susceptibility factors that lead to NTM infections [7].

Toll-like receptors (TLRs) are important patternrecognition receptors that function in the host's innate defence mechanism against invading pathogens, such as Mycobacterium tuberculosis and NTM $[8,9]$. Signalling through these receptors leads to transcription and translation of a variety of cytokines/mediators [10, 11]. TLR2 is required for NTM signalling [12, 13] and increased susceptibility to $M$. avium infection was recently reported in TLR2-knockout mice [14]. Furthermore, mice deficient in myeloid differentiation factor (MyD) 88 were more sensitive to $M$. avium infection [15]. These results suggest that infection with opportunistic $M$. avium species is controlled in a TLR2- and MyD88-dependent manner.

It remains unclear whether the results reliably reflect the mechanisms of pathogenesis and immunity in humans, despite various studies on animals with TLR2 deficiency and cell-culture studies examining the role of TLR2 in NTM
AFFILIATIONS

*Division of Pulmonary and Critical Care Medicine, Dept of Medicine, Samsung Medical Centre,

Sungkyunkwan University School of Medicine, and

\#Dept of Internal Medicine, Ewha Womans University Dongdaemun Hospital, College of Medicine and Ewha Medical Research Institute, Ewha Womans University, Seoul, Republic of Korea.

"Y.J. Ryu and E.J. Kim contributed equally to the present study.

\section{CORRESPONDENCE}

W-J. Koh, Division of Pulmonary and Critical Care Medicine, Dept of Medicine, Samsung Medical Centre, Sungkyunkwan University School of Medicine, 50 Irwon-dong, Gangnam-gu, Seoul 135-710, Korea. Fax: 82234106956

E-mail: wjkoh@skku.edu

Received:

April 032007

Accepted after revision:

June 032007

\section{SUPPORT STATEMENT}

The present study was supported by a grant of the Korea Health 21

Research and Development Project, Ministry of Health and Welfare,

Republic of Korea (A060256).

STATEMENT OF INTEREST

A statement of interest for this study can be found at www.erj.ersjournals.com/misc/ statements.shtml

European Respiratory Journal Print ISSN 0903-1936

Online ISSN 1399-3003 
infection and immunity. In the present study, the expression of TLR2 was investigated on the peripheral blood monocytes of patients with NTM lung disease and healthy controls. The responses of these monocytes to the TLR2 agonists $M$. avium and lipoteichoic acid (LTA) from Staphylococcus aureus were also compared. It was hypothesised that TLR2 expression is lower in patients with NTM lung disease, and thus it was expected that the response of peripheral blood monocytes to TLR2 agonists would be suppressed in NTM patients.

\section{PATIENTS AND METHODS}

\section{Study population}

The present study included 17 patients with the nodular bronchiectatic form of NTM lung disease and 10 healthy volunteers (table 1 ). Of the 17 patients, eight exhibited $M$. avium-intracellulare complex infection and nine exhibited $M$. abscessus infection. The diagnosis of NTM lung disease was made according to the diagnostic criteria published by the American Thoracic Society [1], and all patients had characteristic findings on high-resolution computed tomography scans, such as bilateral bronchiectasis combined with multiple small nodules and branching linear structures [16]. Peripheral blood samples of $30 \mathrm{~mL}$ were obtained from both groups before antibiotic therapy was initiated. The study was approved by the institutional review board of the Samsung Medical Centre

\begin{tabular}{|c|c|c|}
\hline TABLE 1 & \multicolumn{2}{|c|}{$\begin{array}{l}\text { Clinical characteristics of patients with } \\
\text { nontuberculous mycobacterial lung disease }\end{array}$} \\
\hline \multicolumn{3}{|c|}{ Characteristics } \\
\hline Patients $\mathrm{n}$ & & 17 \\
\hline Age yrs & & $59(52-64)$ \\
\hline \multicolumn{3}{|l|}{ Sex } \\
\hline Male & & $2(12)$ \\
\hline Female & & $15(88)$ \\
\hline Body mass & $\operatorname{dex} \mathbf{k g} \cdot \mathrm{m}^{-2}$ & $20.4(19.2-21.0)$ \\
\hline \multicolumn{3}{|c|}{ Aetiology } \\
\hline M. avium-i & racellulare complex & $8(47)$ \\
\hline M. absces & & $9(53)$ \\
\hline \multicolumn{3}{|c|}{ Sputum AFB smear } \\
\hline Negative & & $9(53)$ \\
\hline Positive & & $8(47)$ \\
\hline \multicolumn{3}{|c|}{ Smoking history } \\
\hline Nonsmoke & & $17(100)$ \\
\hline \multicolumn{3}{|c|}{ Presenting symptoms } \\
\hline Cough & & $15(88)$ \\
\hline Sputum & & $12(71)$ \\
\hline Haemopty & & $7(41)$ \\
\hline \multicolumn{3}{|c|}{ Underlying diseases } \\
\hline Bronchiect & & $17(100)$ \\
\hline Sinusitis & & $4(24)$ \\
\hline History of & perculosis & $3(18)$ \\
\hline Diabetes $n$ & llitus & $3(18)$ \\
\hline
\end{tabular}

Data are presented as $\mathrm{n}(\%)$ or median (interquartile range), unless otherwise stated. M. avium: Mycobacterium avium; M. abscessus: Mycobacterium abscessus; AFB: acid-fast bacilli.
(Seoul, Republic of Korea), and written informed consent was obtained from all participants.

\section{Preparation and stimulation of peripheral monocytes}

Peripheral blood mononuclear cells were separated from heparinised whole blood using standard density gradient centrifugation with Ficoll-Hypaque (Sigma, St. Louis, MO, USA). The cells were cultured for $2 \mathrm{~h}$ and washed with Dulbecco's PBS (Sigma) to remove nonadherent cells. To ascertain whether adherent cells were monocytes, the cells were labelled with anti-CD14-fluorescein isothiocyanate (FITC) and examined by flow cytometry. For flow cytometric analysis, FITC-labelled anti-CD14 was purchased from eBioscience (San Diego, CA, USA) and analysed by flow cytometry using a FACScan flow cytometer (Becton Dickinson Immunocytometry, San Jose, CA, USA). Monocytes $\left(1 \times 10^{6}\right.$ cells $\left.\cdot \mathrm{mL}^{-1}\right)$ were then stimulated with $M$. avium (American Type Culture Collection 25291; $1 \times 10^{6}$ colony-forming units $\cdot$ well $^{-1}$ ) or LTA from $S$. aureus $\left(10 \mu \mathrm{g} \cdot \mathrm{mL}^{-1}\right.$; InvivoGen, San Diego, CA, USA) for $0,2,4,6$ and $24 \mathrm{~h}$ at $37^{\circ} \mathrm{C}$.

\section{Total RNA isolation, cDNA synthesis and RT-PCR}

Total RNA was isolated using $\mathrm{RNAzol}^{\mathrm{TM}} \mathrm{B}$ (Invitrogen Life Technologies, San Diego, CA, USA), and cDNA synthesis and reverse transcriptase (RT)-PCR were performed using the AccessQuick (IM) RNA-PCR system (Promega, Madison, WI, USA). The first-strand cDNA was synthesised from the total RNA at $45^{\circ} \mathrm{C}$ for $45 \mathrm{~min}$ in a DNA thermal cycler (Hybaid, Teddington, UK). Forty cycles of PCR amplification were subsequently performed. The amplified PCR product was confirmed on a $2 \%$ agarose gel, and the gel bands were analysed quantitatively using a PhosphorImager with Bio-1D V.97 software for Windows 95 (Vilber Lourmat, Marne-laVallée, France). The primers for amplification of TLR2, interleukin (IL)-12 p40 and tumour necrosis factor (TNF)- $\alpha$ cDNAs are shown in table 2. RT-PCR was performed before stimulation with TLR2 agonists and again at 2, 4, 6 and $24 \mathrm{~h}$ after stimulation.

\begin{tabular}{|c|c|}
\hline TABLE 2 & $\begin{array}{l}\text { Primer sequences used for reverse } \\
\text { transcriptase-PCR analysis of mRNA expression } \\
\text { levels for } \beta \text {-actin, Toll-like receptor (TLR)2, } \\
\text { interleukin (IL)-12 p40 and tumour necrosis factor } \\
\text { (TNF)- } \alpha\end{array}$ \\
\hline Gene & Primer sequence $\left(5^{\prime} \rightarrow 3^{\prime}\right)$ \\
\hline \multicolumn{2}{|l|}{$\beta$-actin } \\
\hline Sense & ATG GAG AAA ATC TGG CAC CA \\
\hline Antisense & AAT GGT GAT GAC CTG GCC CT \\
\hline \multicolumn{2}{|l|}{ TLR2 } \\
\hline Sense & ACC TTA TGG TCC AGG AGC TG \\
\hline Antisense & TGC ACC ACT CAC TCT TCA CA \\
\hline \multicolumn{2}{|l|}{ IL-12 p40 } \\
\hline Sense & GAT GGA ATT TGG TCC ACT AA \\
\hline Antisense & CGG CAT GGA CCA TGA CCT CA \\
\hline \multicolumn{2}{|l|}{ TNF- $\alpha$} \\
\hline Sense & CCA TGA GCA CTG AAA GCA TG \\
\hline Antisense & TCA CAG GGC AAT GAT CCC AA \\
\hline
\end{tabular}


a)
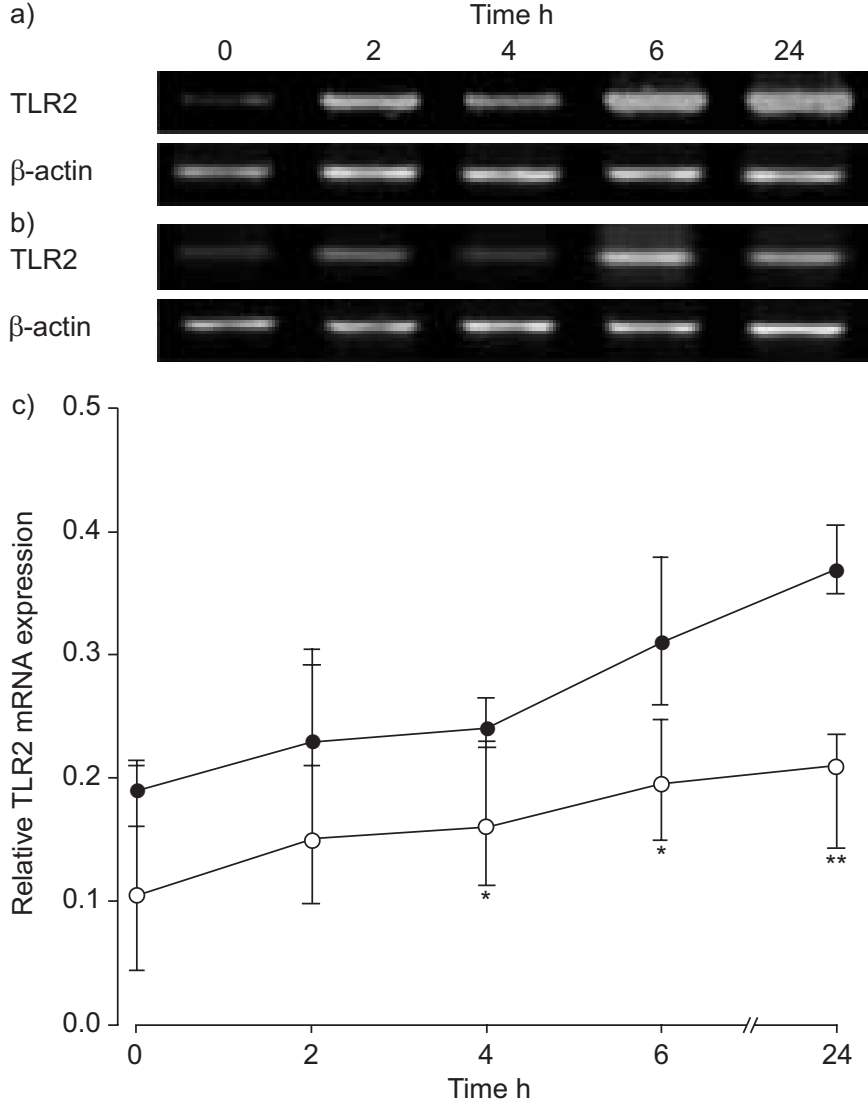

FIGURE 1. Mycobacterium avium-induced Toll-like receptor (TLR)2 mRNA expression in peripheral blood monocytes from patients with nontuberculous mycobacteria (NTM) lung disease and healthy controls. Peripheral blood monocytes were plated in a 24-well dish at $1 \times 10^{6}$ cells well ${ }^{-1}$ and then treated with $M$. avium American Type Culture Collection 25291 ( $10^{6}$ colony-forming units) for the indicated lengths of time. a, b) TLR2 mRNA expression was assessed by reverse transcriptase-PCR analysis of isolated total RNA (600 ng) using $\beta$-actin as a control. Data shown represent: a) NTM lung disease patients $(n=17)$ and $b)$ independent healthy controls $(n=7)$. c) TLR2 mRNA expression levels of patient and control monocytes, presented as median (25th-75th interquartile range). TLR2 mRNA expression was significantly lower in patients $(O)$ than in controls $(\bullet)$ after $4 \mathrm{~h}$ of stimulation with M. Avium. *: $p<0.05 ;{ }^{* *}: p<0.01$.

\section{Cytokine assays}

At $0,2,4,6$ and $24 \mathrm{~h}$ after stimulation of monocytes with either $M$. avium or LTA, cell-free (cleared) supernatant fractions were collected and analysed for cytokine release. The supernatants were stored in aliquots at $-70^{\circ} \mathrm{C}$ until used in experiments. Concentrations of IL-12 p40 and TNF- $\alpha$ were determined using commercially available ELISA kits (Biosource, Camarillo, CA, USA).

\section{Addition of anti-human TLR2 antibody}

A blocking experiment with anti-human TLR2 antibody was performed to examine whether a TLR2 signalling blockade would reduce TLR2 agonist-induced cytokine production. Before $M$. avium or LTA stimulation, peripheral blood monocytes were pre-incubated with anti-TLR2 antibody (10 $\mu \mathrm{g} \cdot \mathrm{mL}^{-1}$; eBioscience) at room temperature for $30 \mathrm{~min}$. The cells were then stimulated with M. avium or LTA for $24 \mathrm{~h}$. RT-PCR and cytokine assays were performed to determine
IL-12 p40 and TNF- $\alpha$ mRNA and protein secretion levels, respectively.

\section{Statistical analysis}

The majority of data were not normally distributed. Therefore, all values were expressed as medians and interquartile range (25th and 75th percentiles) and the data were analysed using nonparametric analysis. Differences in each variable between patients and controls were evaluated with Mann-Whitney Utests. A p-value $<0.05$ was considered statistically significant.

\section{RESULTS}

Expression of TLR2 mRNA in peripheral blood monocytes

The present authors first examined the kinetics of expression of TLR2 mRNA in peripheral blood monocytes from healthy controls in response to two different TLR2 agonists, $M$. avium and LTA. The level of TLR2 mRNA increased within $2 \mathrm{~h}$ postinfection with $M$. avium. RT-PCR analysis showed a timedependent increase in TLR2 mRNA expression in healthy controls (fig. 1). The extent of TLR2 mRNA induction caused by LTA in these control monocytes was similar to that caused by $M$. avium (data not shown).

Unstimulated monocytes from NTM patients exhibited decreased TLR2 mRNA levels compared with those of controls, although this difference was not statistically significant. After stimulation with M. avium, TLR2 mRNA levels increased slightly, with a gentle slope. Compared with controls, TLR2 mRNA levels of patients were significantly lower at $4 \mathrm{~h}$ post-infection ( $\mathrm{p}<0.05$ at 4,6 and $24 \mathrm{~h}$; fig. 1$)$. LTA stimulation affected TLR2 mRNA expression similarly to $M$. avium infection (data not shown).

\section{Expression of IL-12 p40 and TNF- $\alpha$ mRNA}

A comparative analysis of $M$. avium-induced cytokine gene expression was performed in NTM patients and healthy controls. In healthy controls, $M$. avium stimulation caused levels of mRNA for both IL-12 p40 and TNF- $\alpha$ to increase in a time-dependent manner. Expression in unstimulated and $M$. avium-stimulated monocytes was significantly lower in patients than in healthy controls $(\mathrm{p}<0.05$ at all time-points; fig. 2). LTA stimulation had effects similar to those of M. avium infection (data not shown).

\section{IL-12 p40 and TNF- $\alpha$ secretion}

The present authors also compared IL-12 p40 and TNF- $\alpha$ production response of patient and control monocytes to stimulation with $M$. avium or LTA, using an ELISA kit. The concentrations of IL-12 p40 and TNF- $\alpha$ in unstimulated and $M$. avium-stimulated monocytes were significantly lower in patients than in controls $(\mathrm{p}<0.05$ at all time-points except TNF- $\alpha$ levels at $4 \mathrm{~h}$; fig. 3). LTA stimulation yielded similar results (data not shown).

\section{Inhibitory effect of anti-TLR2 antibody on IL-12 p40 and TNF- $\alpha$ production}

Finally, monocytes were stimulated with M. avium or LTA in the presence or absence of anti-TLR2 antibody. As shown in figure 4, antibody treatment substantially inhibited $M$. aviuminduced IL-12 p40 production in healthy controls, a level of inhibition far greater than that observed in patients (50 versus $8 \%$ inhibition). Antibody treatment also reduced 
a)
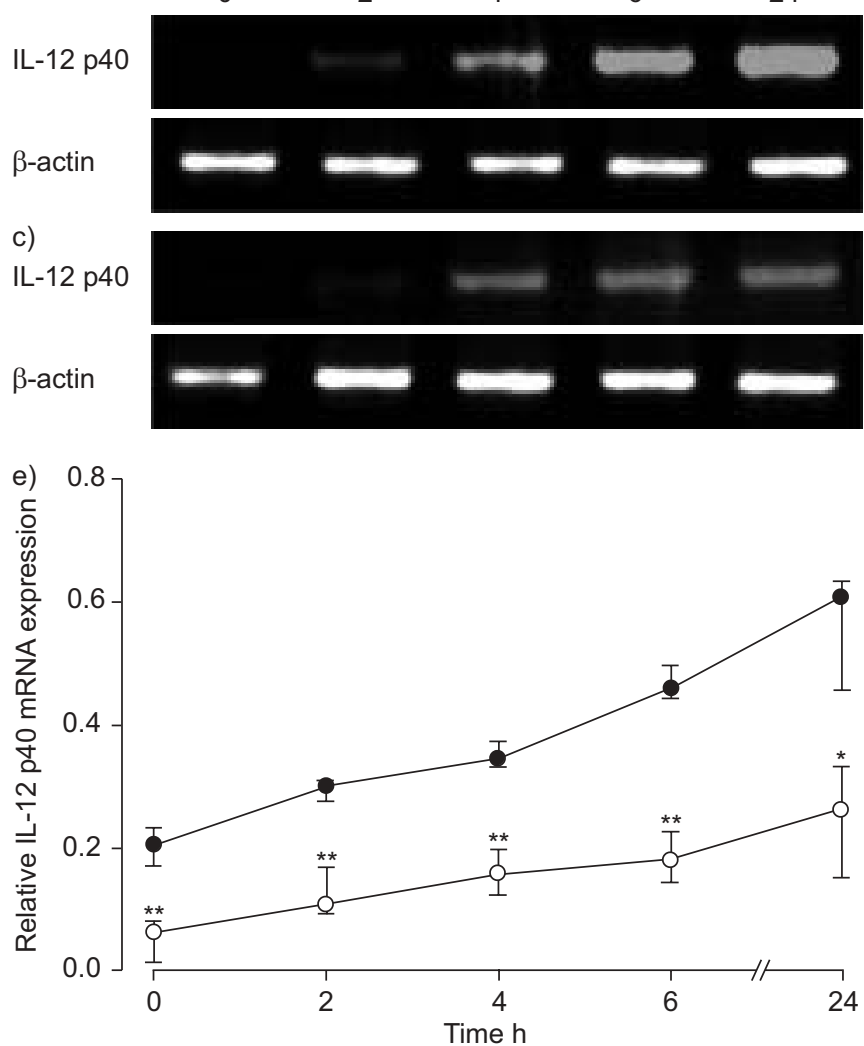

b)

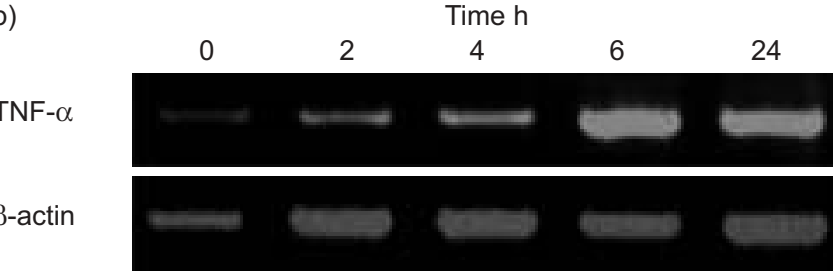

d)

TNF- $\alpha$
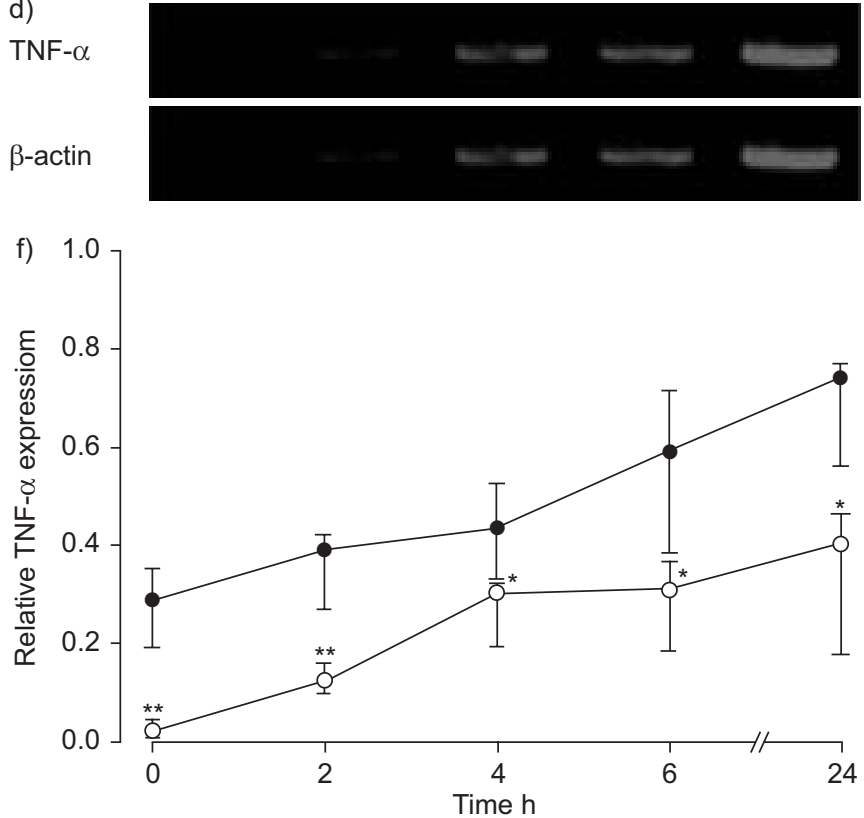

FIGURE 2. Mycobacterium avium-induced interleukin (IL)-12 p40 and tumour necrosis factor (TNF)- $\alpha$ mRNA expression in peripheral blood monocytes from nontuberculous mycobacteria (NTM) patients and from healthy controls. Peripheral blood monocytes were infected with M. avium American Type Culture Collection 25291 ( $10^{6}$ colony-forming units) for the indicated lengths of time. Expression of $\left.a, c\right) \mathrm{IL}-12$ p40 and b, d) TNF- $\alpha$ mRNA was assessed by reverse transcriptase PCR analysis using $\beta$ actin as a control. Data shown represent 12 patients (c, d) and four controls (a, b). e) IL-12 p40 and f) TNF- $\alpha$ mRNA expression levels are presented as median (25th-75th interquartile range). Expression of these mRNAs was significantly lower in unstimulated and $M$. avium-stimulated monocytes of patients than in those of controls. *: $p<0.05$; $* *: p<0.01$.

M. avium-induced TNF- $\alpha$ synthesis to a greater extent in controls than in patients (51 versus $24 \%$ ). In addition, posttreatment cytokine secretion was significantly lower (six- and two-fold lower for IL-12 p40 and TNF- $\alpha$, respectively) for monocytes from healthy controls than for those from patients. However, antibody treatment did not significantly change IL12 p40 or TNF- $\alpha$ secretion responses of patient monocytes to stimulation with $M$. avium or LTA.

\section{DISCUSSION}

To the present authors' knowledge, the current study is the first to examine TLR2 mRNA expression and its relationship to cytokine responses in patients with NTM lung disease. The present data demonstrate that both $M$. avium and LTA induce TLR2 mRNA expression in peripheral blood monocytes from healthy controls and, subsequently, upregulate IL-12 p40 and TNF- $\alpha$ expression and production. In peripheral blood monocytes from NTM patients, however, the induction of TLR2 mRNA expression (and of IL-12 p40 and TNF- $\alpha$ expression and production) occurred to a significantly lesser extent. Thus, the current findings suggest that impaired induction of TLR2 expression in response to $M$. avium or LTA stimulation may contribute to host susceptibility to NTM lung disease.
Since nontuberculous mycobateria are ubiquitous organisms, most animals are resistant to NTM infection unless their defence mechanisms have undergone iatrogenic alteration. However, the nature of the precise immune dysfunction that predisposes otherwise healthy subjects to NTM lung disease is not clear. A few studies that have compared the immune activation of peripheral blood mononuclear cells from NTM patients and healthy controls $[17,18]$ have shown that patients produce lower concentrations of IL-12 and TNF- $\alpha$ and higher concentrations of IL-10 in response to various antigens. These results suggest that the T-helper cell (Th) type 1 immune response in NTM patients is suppressed, whereas the Th2-type reaction is augmented. Therefore, deficiencies in the type- 1 cytokine cascade might enhance susceptibility to NTM infection. However, the mechanisms responsible for this immunological imbalance remain unknown.

TLR2 is critical to the immune response to NTM infection and it is required for induction of IL-12, which plays a major role in promoting Th1 responses [8-11]. Infection of murine macrophages with $M$. avium was previously shown to upregulate TLR2 mRNA expression [12, 13], and TLR2 activation induces early production of IL-12 and TNF- $\alpha$ from specific phagocyte subsets. Previous in vitro studies showed that TLR2 stimulation is 

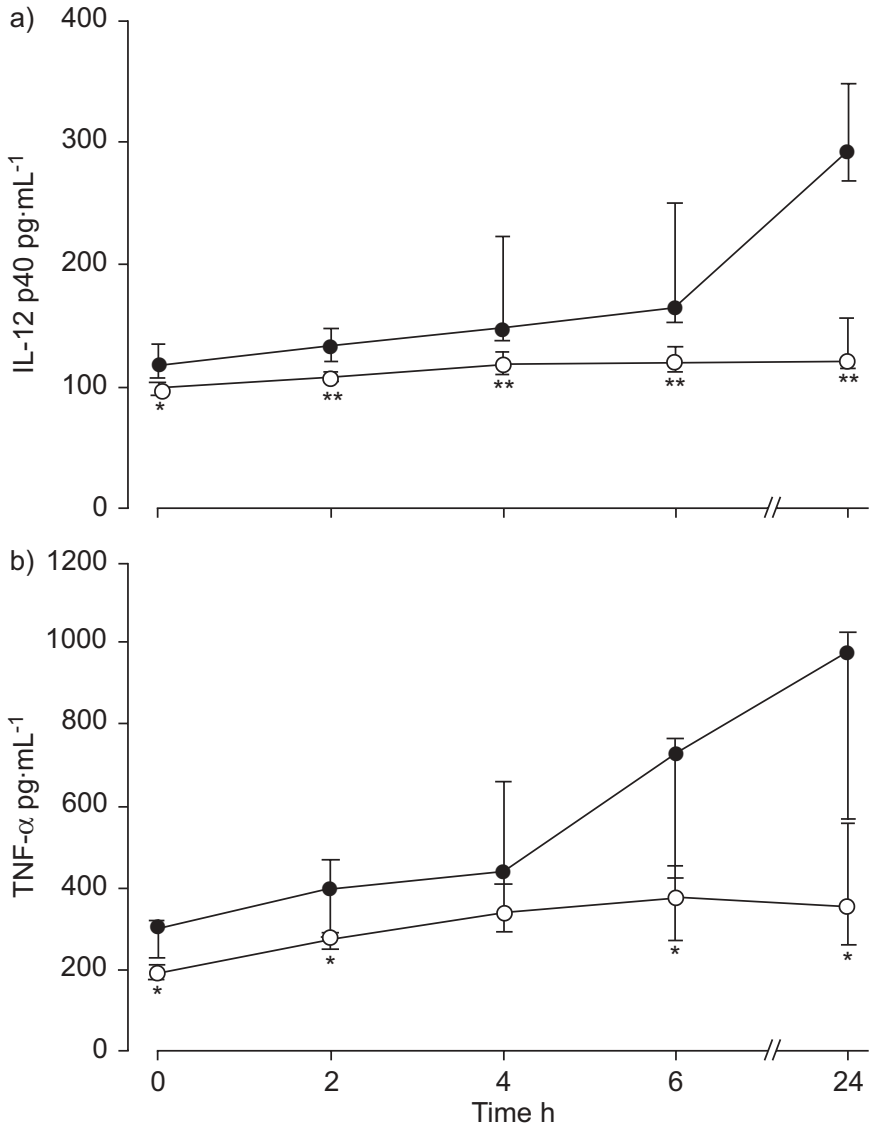

FIGURE 3. Mycobacterium avium-induced a) interleukin (IL)-12 p40 and b) tumour necrosis factor (TNF)- $\alpha$ production in peripheral blood monocytes from nontuberculous mycobacteria patients $(O ; n=17)$ and healthy controls $(\bullet ; n=7)$. Peripheral blood monocytes were infected with $M$. avium American Type Culture Collection 25291 ( $10^{6}$ colony-forming units) for the indicated lengths of time. Cellfree supernatants, cleared by centrifugation, were harvested at the indicated times and secretion of IL-12 p40 and TNF- $\alpha$ cytokines was assessed using ELISA. Data are presented as median (25th-75th interquartile range). ${ }^{*}: p<0.05$; ${ }^{*}$ : $p<0.01$.

responsible for $M$. avium-induced upregulation of proinflammatory Th1 cytokines in mouse macrophages [12, 13, 19]. Furthermore, TLR2 plays an important role in controlling NTM infection in animal studies. For example, control of $M$. bovis bacillus Calmette-Guerin in mice after i.p. infection was dependent on TLR2 [20] and FENG et al. [15] found that mice deficient in TLR2 had increased bacterial load and increased susceptibility to $M$. avium infection compared with wild-type mice.

Although these findings strongly suggest that regulation of TLR2 expression is an important determinant of NTM lung disease susceptibility, the relationship between NTM lung disease and TLR2 and cytokine expression has not been studied previously. In the present study, it was found that $M$. avium and LTA downregulated TLR2 mRNA expression, and IL-12 p40 and TNF- $\alpha$ production in peripheral blood monocytes of NTM patients. In addition, treatment with anti-TLR2 antibody blocked M. avium- and LTA-induced cytokine gene production and subsequent cytokine secretion in monocytes of healthy controls, but had only a minimal effect in those of patients. These results indicate that M. avium- and LTAinduced activation of IL-12 p40 and TNF- $\alpha$ are mediated primarily by TLR2.

IL-12 is a major stimulus for interferon- $\gamma$ production and it plays a pivotal role in forming a major link between innate and adaptive immunity [21, 22]. TNF- $\alpha$ is essential for the development of protective immunity against mycobacterial disease [23]. Taken together with the cytokine profiles of NTM patients [17, 18], the present data suggest that downregulation of TLR2 may play a key role in mediating the impairment of host defence, and support the hypothesis that TLR2 deficiency plays an important role in host susceptibility to NTM lung disease.

Recent studies of TLR2 polymorphisms have shown the importance of TLR in human mycobacterial diseases. The Arg677Trp polymorphism of TLR2 is associated with lepromatous leprosy [24] and pulmonary tuberculosis [25], and the Arg753Gln polymorphism of TLR2 is associated with tuberculosis [26]. In addition, guanine-thymine repeat polymorphisms in intron II of the TLR2 gene are associated with the development of tuberculosis [27]. However, whether these genetic polymorphisms determine the susceptibility to NTM lung disease is unknown [28].

The present study has several important limitations. The gene expression in cells in the peripheral blood may not reflect the gene expression response in the lung, which is the actual site of NTM infection. Peripheral blood monocytes can reflect the immunoreactivity of airway cells, but the immune response of peripheral blood monocytes may be confounded due to a lack of local immunoregulatory mechanisms present in the lung $[29,30]$. Therefore, further studies involving TLR2 mRNA expression and subsequent cytokine immune responses using bronchoalveolar lavage cells or lung tissue are needed.

In addition, although downregulation of TLR2 and a resulting decreased production of IL-12 p40 and TNF- $\alpha$ following $M$. avium or LTA stimulation in patients with NTM lung disease was found, the nature of this relationship remains uncertain. The present data are consistent with the downregulation of TLR2 causing or contributing to the development of NTM lung disease via decreased production of IL-12 p40 and TNF- $\alpha$. Alternatively, the downregulation of TLR2 might be a secondary phenomenon. It may also be possible that the NTM infection led to the differences observed in the present study. Further studies including patients after successful treatment of NTM lung disease would be needed.

In conclusion, Toll-like receptor 2 mRNA expression in response to stimulation with Mycobacterium avium or lipoteichoic acid is lower in peripheral blood monocytes from patients with nontuberculous mycobaterial lung disease than in those from healthy controls. Lipoteichoic acidand Mycobacterium avium-induced mRNA expression and interleukin-12 p40 and tumour necrosis factor- $\alpha$ production were also lower in patients than in controls. Thus, the present findings suggest that the downregulation of Toll-like receptor 2 and the subsequent decrease in interleukin-12 p40 and tumour necrosis factor- $\alpha$ production following Mycobacterium avium infection may contribute to host susceptibility to nontuberculous mycobaterial lung disease. This disease is associated with 
a) IL-12 p40

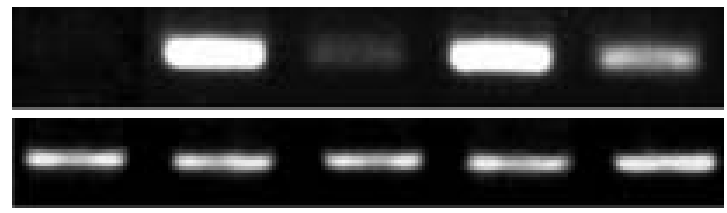

TNF- $\alpha$

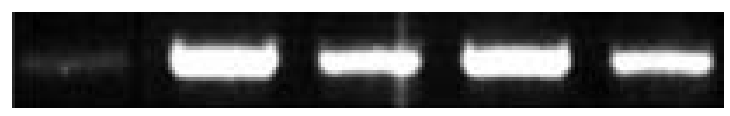

$\beta$-actin

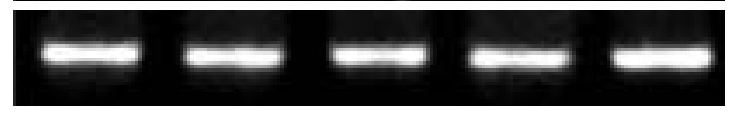

\section{M. avium}

LTA

\section{Anti-TLR2} antibody

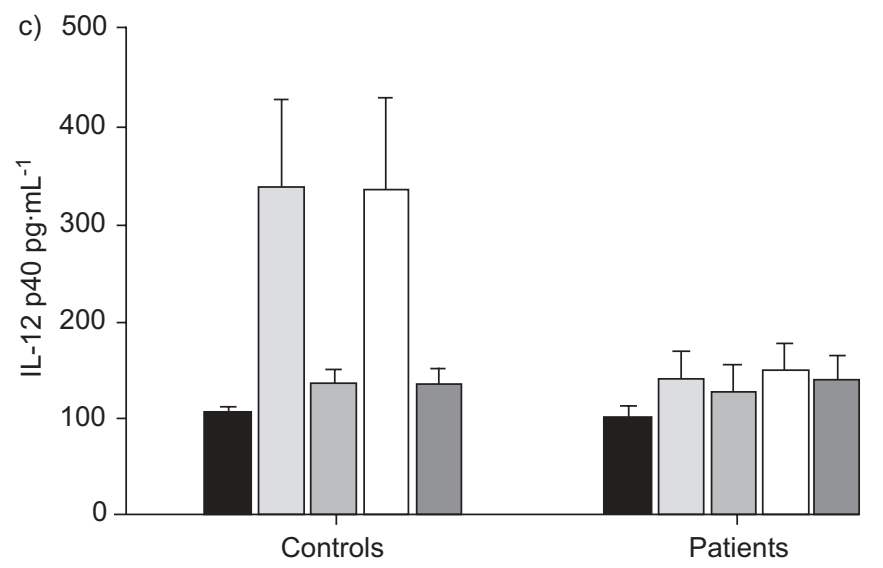

b)
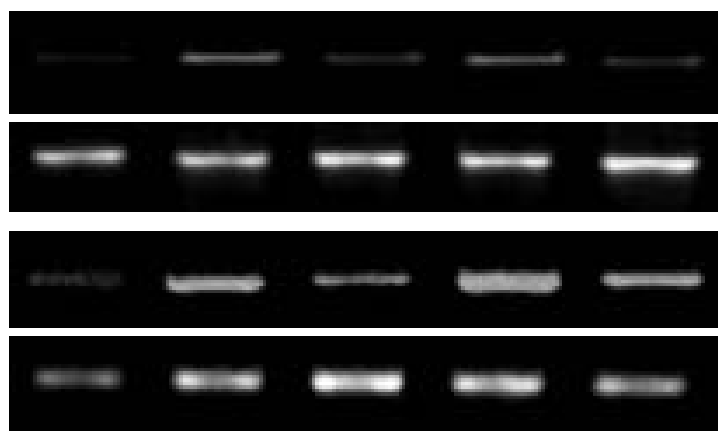

d)

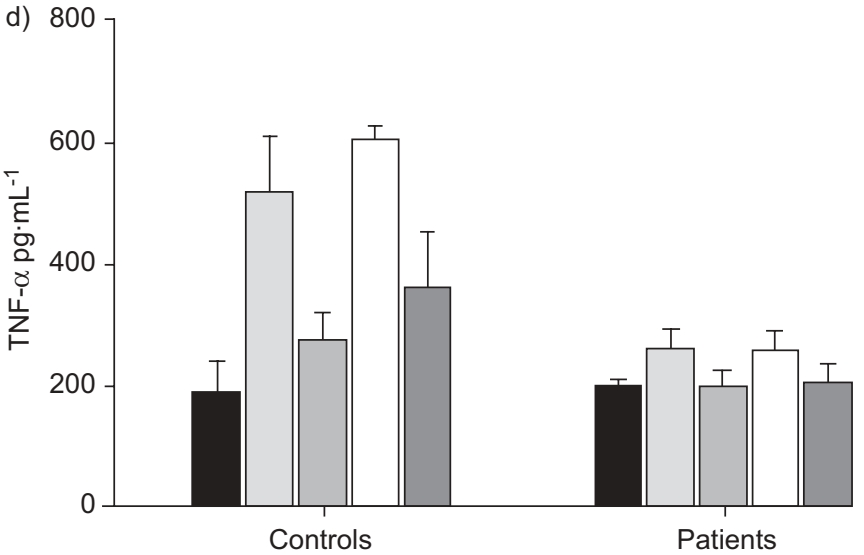

FIGURE 4. Inhibitory effect of anti-Toll-like receptor (TLR)2 antibody on Mycobacterium avium-induced interleukin (IL)-12 p40 and tumour necrosis factor (TNF)- $\alpha$ production in peripheral blood monocytes from nontuberculous mycobacteria (NTM) patients and healthy controls. The antibody $\left(10 \mu \mathrm{g} \cdot \mathrm{mL}^{-1}\right)$ was added to peripheral blood monocytes 30 min before stimulation with M. avium American Type Culture Collection 25291 (10 colony-forming units) or lipoteichoic acid (LTA) for $24 \mathrm{~h}$. a) Total RNA was isolated and expression of IL-12 p40 and TNF- $\alpha$ mRNA was determined in a) healthy controls and b) NTM patients by reverse transcriptase-PCR analysis using $\beta$-actin as a control. Data shown represent four patients and three controls. The culture supernatants were harvested for c) IL-12 p40 and d) TNF- $\alpha$ cytokine assessment using ELISA after

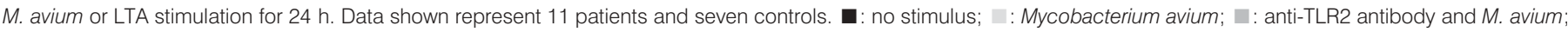
$\square:$ LTA; $\mathbb{1}:$ : anti-TLR2 antibody and LTA.

substantial morbidity; current treatment strategies using chronic, multidrug therapy are ineffective and can have a variety of side-effects. Understanding the precise mechanisms responsible for downregulation of Toll-like receptor 2 and the associated decrease in interleukin-12 p40 and tumour necrosis factor- $\alpha$ production may facilitate the development of immunomodulatory strategies to treat or prevent nontuberculous mycobaterial lung disease.

\section{REFERENCES}

1 Wallace RJ Jr, Cook JL, Glassroth J, Griffith DE, Olivier KN, Gordin F. American Thoracic Society statement: diagnosis and treatment of disease caused by nontuberculous mycobacteria. Am J Respir Crit Care Med 1997; 156: S1-S25.

2 Griffith DE, Aksamit T, Brown-Elliott BA, et al. An official ATS/IDSA statement: diagnosis, treatment, and prevention of nontuberculous mycobacterial diseases. Am J Respir Crit Care Med 2007; 175: 367-416.
3 Dailloux M, Abalain ML, Laurain C, et al. Respiratory infections associated with nontuberculous mycobacteria in non-HIV patients. Eur Respir J 2006; 28: 1211-1215.

4 Koh WJ, Kwon OJ, Lee KS. Diagnosis and treatment of nontuberculous mycobacterial pulmonary diseases: a Korean perspective. J Korean Med Sci 2005; 20: 913-925.

5 Guide SV, Holland SM. Host susceptibility factors in mycobacterial infection. Genetics and body morphotype. Infect Dis Clin North Am 2002; 16: 163-186.

6 Hwang JH, Koh WJ, Kim EJ, et al. Partial interferon- $\gamma$ receptor deficiency and non-tuberculous mycobacterial lung disease. Tuberculosis (Edinb) 2006; 86: 382-385.

7 Koh WJ, Kwon OJ, Kim EJ, Lee KS, Ki CS, Kim JW. NRAMP1 gene polymorphism and susceptibility to nontuberculous mycobacterial lung diseases. Chest 2005; 128 : 94-101.

8 Quesniaux V, Fremond C, Jacobs M, et al. Toll-like receptor pathways in the immune responses to mycobacteria. Microbes Infect 2004; 6: 946-959. 
9 Ryffel B, Fremond C, Jacobs M, et al. Innate immunity to mycobacterial infection in mice: critical role for Toll-like receptors. Tuberculosis (Edinb) 2005; 85: 395-405.

10 Heldwein KA, Fenton MJ. The role of Toll-like receptors in immunity against mycobacterial infection. Microbes Infect 2002; 4: 937-944.

11 Akira S, Takeda K. Toll-like receptor signalling. Nat Rev Immunol 2004; 4: 499-511.

12 Wang T, Lafuse WP, Zwilling BS. Regulation of Toll-like receptor 2 expression by macrophages following Mycobacterium avium infection. J Immunol 2000; 165: 6308-6313.

13 Alvarez GR, Zwilling BS, Lafuse WP. Mycobacterium avium inhibition of IFN- $\gamma$ signaling in mouse macrophages: Toll-like receptor 2 stimulation increases expression of dominant-negative STAT1 $\beta$ by mRNA stabilization. J Immunol 2003; 171: 6766-6773.

14 Gomes MS, Flórido M, Cordeiro JV, et al. Limited role of the Toll-like receptor-2 in resistance to Mycobacterium avium. Immunology 2004; 111: 179-185.

15 Feng CG, Scanga CA, Collazo-Custodio CM, et al. Mice lacking myeloid differentiation factor 88 display profound defects in host resistance and immune responses to Mycobacterium avium infection not exhibited by Toll-like receptor 2 (TLR2)- and TLR4-deficient animals. J Immunol 2003; 171: 4758-4764.

16 Koh WJ, Lee KS, Kwon OJ, Jeong YJ, Kwak SH, Kim TS. Bilateral bronchiectasis and bronchiolitis at thin-section CT: diagnostic implications in nontuberculous mycobacterial pulmonary infection. Radiology 2005; 235: 282-288.

17 Greinert U, Schlaak M, Rüsch-Gerdes S, Flad HD, Ernst M. Low in vitro production of interferon- $\gamma$ and tumor necrosis factor- $\alpha$ in HIV-seronegative patients with pulmonary disease caused by nontuberculous mycobacteria. J Clin Immunol 2000; 20: 445-452.

18 Vankayalapati R, Wizel B, Samten B, et al. Cytokine profiles in immunocompetent persons infected with Mycobacterium avium complex. J Infect Dis 2001; 183: 478-484.

19 Underhill DM, Ozinsky A, Smith KD, Aderem A. Toll-like receptor-2 mediates mycobacteria-induced proinflammatory signaling in macrophages. Proc Natl Acad Sci USA 1999; 96: 14459-14463.
20 Heldwein KA, Liang MD, Andresen TK, et al. TLR2 and TLR4 serve distinct roles in the host immune response against Mycobacterium bovis BCG. J Leukoc Biol 2003; 74: 277-286.

21 Sieling PA, Chung W, Duong BT, Godowski PJ, Modlin RL. Toll-like receptor 2 ligands as adjuvants for human Th1 responses. J Immunol 2003; 170: 194-200.

22 Trinchieri G. Interleukin-12 and the regulation of innate resistance and adaptive immunity. Nat Rev Immunol 2003; 3: $133-146$.

23 Gomez-Flores R, Tucker SD, Kansal R, Tamez-Guerra R, Mehta RT. Enhancement of antibacterial activity of clofazimine against Mycobacterium avium-Mycobacterium intracellulare complex infection induced by IFN- $\gamma$ is mediated by TNF- $\alpha$. J Antimicrob Chemother 1997; 39: 189-197.

24 Kang TJ, Chae GT. Detection of Toll-like receptor 2 (TLR2) mutation in the lepromatous leprosy patients. FEMS Immunol Med Microbiol 2001; 31: 53-58.

25 Ben-Ali M, Barbouche MR, Bousnina S, Chabbou A, Dellagi K. Toll-like receptor 2 Arg677Trp polymorphism is associated with susceptibility to tuberculosis in Tunisian patients. Clin Diagn Lab Immunol 2004; 11: 625-626.

26 Ogus AC, Yoldas B, Ozdemir T, et al. The Arg753Gln polymorphism of the human Toll-like receptor 2 gene in tuberculosis disease. Eur Respir J 2004; 23: 219-223.

27 Yim JJ, Lee HW, Lee HS, et al. The association between microsatellite polymorphisms in intron II of the human Toll-like receptor 2 gene and tuberculosis among Koreans. Genes Immun 2006; 7: 150-155.

28 Ryu YJ, Kim EJ, Koh WJ, Kim H, Kwon OJ, Chang JH. Toll-like receptor 2 polymorphisms and nontuberculous mycobacterial lung diseases. Clin Vaccine Immunol 2006; 13: 818-819.

29 Sable SB, Goyal D, Verma I, Behera D, Khuller GK. Lung and blood mononuclear cell responses of tuberculosis patients to mycobacterial proteins. Eur Respir J 2007; 29: 337-346.

30 Schwander SK, Torres M, Carranza CC, et al. Pulmonary mononuclear cell responses to antigens of Mycobacterium tuberculosis in healthy household contacts of patients with active tuberculosis and healthy controls from the community. J Immunol 2000; 165: 1479-1485. 